\title{
Peptidyl-Prolyl Isomerase 1 Regulates Protein Phosphatase 2A-Mediated Topographic Phosphorylation of Neurofilament Proteins
}

\author{
Parvathi Rudrabhatla, Wayne Albers, and Harish C. Pant \\ Laboratory of Neurochemistry, National Institutes of Neurological Disorders and Stroke, National Institutes of Health, Bethesda, Maryland 20892
}

In normal neurons, neurofilament (NF) proteins are phosphorylated in the axonal compartment. However, in neurodegenerative disorders such as Alzheimer's disease (AD), Parkinson's disease (PD), and amyotrophic lateral sclerosis (ALS), NF proteins are aberrantly hyperphosphorylated within the cell bodies. The aberrant hyperphosphorylation of NF accumulations found in neurodegeneration could be attributable to either deregulation of proline-directed Ser/Thr kinase(s) activity or downregulation of protein phosphatase(s) activity. In this study, we found that protein phosphatase $2 \mathrm{~A}$ (PP2A) expression is high in neuronal cell bodies and that inhibition of PP2A activity by okadaic acid (OA), microcystin LR (mLR), or fostriecin (Fos) leads to perikaryal hyperphosphorylation of NF. Peptidyl-prolyl isomerase Pin1 inhibits the dephosphorylation of NF by PP2A in vitro. In cortical neurons, Pin1 modulates the topographic phosphorylation of the proline-directed Ser/Thr residues within the tail domain of NF proteins by inhibiting the dephosphorylation by PP2A. Inhibition of Pin1 inhibits OA-induced aberrant perikaryal phosphorylation of NF. Treatment of cortical neurons with OA or Fos prevents the general anterograde transport of transfected green fluorescent protein-high-molecular-mass (NF-H) into axons caused by hyperphosphorylation of NF-H, and inhibition of Pin1 rescues this effect. Furthermore, inhibition of Pin1 inhibits the 0A- or Fos-induced neuronal apoptosis. We show that $\mathrm{OA}$-induced hyperphosphorylation of NF is a consequence of dephosphorylation of NF and is independent of c-Jun N-terminal protein kinase, extracellular signal-regulated kinase, and cyclin-dependent kinase- 5 pathways. This study highlights a novel signaling role of PP2A by Pin1 and implicates Pin1 as a therapeutic target to reduce aberrant phosphorylation of NF proteins in neurodegenerative disorders such as AD, PD, and ALS.

\section{Introduction}

Neuronal cytoskeletal proteins including neurofilaments (NFs) are extensively phosphorylated on the proline-directed Ser/Thr residues selectively within the axonal compartment under normal physiological conditions (Jaffe et al., 1998). Under pathological conditions such as Alzheimer's disease (AD), Parkinson's disease (PD), and amyotrophic lateral sclerosis (ALS), NFs are aberrantly hyperphosphorylated within the cell bodies (Sternberger et al., 1985; Goldman and Yen, 1986; Lee et al., 1988; Manetto et al., 1988; Veeranna et al., 1995). The underlying mechanisms of this compartment-specific phosphorylation are still unclear. The aberrant hyperphosphorylation of NFs observed in these neurological disorders might be attributable to increased kinase(s) activity, decreased phosphatase(s) activity, or both. NFs are composed of triplet proteins of low (NF-L), medium (NF-M), and high (NF-H) molecular mass. The Lys-Ser-Pro (KSP) motif is represented 52 times in the rat NF-H tail domain (Chin and

Received Sept. 9, 2009; revised 0ct. 7, 2009; accepted 0ct. 13, 2009.

This work was supported by the National Institutes of Health intramural research programs of National Institute of Neurological Disorders and Stroke. We thank Christine Winters for providing rat cortices. We thank Dr. Veeranna for helpful discussions.

Correspondence should be addressed to Dr. Harish C. Pant, Cytoskeletal Regulatory Protein Section, Laboratory of Neurochemistry, National Institute of Neurological Disorders and Stroke, National Institutes of Health, Building 49, Room 2A28, Bethesda, MD 20892. E-mail: panth@ninds.nih.gov.

D0I:10.1523/JNEUROSCI.4469-09.2009

Copyright $\odot 2009$ Society for Neuroscience $\quad$ 0270-6474/09/2914869-12\$15.00/0
Liem, 1990). In vivo, the tail domain of NF can be extensively phosphorylated on almost all the SP repeats (Eagles et al., 1990; Jaffe et al., 1998; Veeranna et al., 1998).

Protein kinases that can phosphorylate NF proteins have been characterized, but much less is known about the protein phosphatases (PPs) in the nervous system (Sim, 1991), especially those acting on NFs. Previous studies demonstrated the presence of a protein phosphatase 2A (PP2A) activity in high-salt extracts of NF preparations from bovine and rat spinal cord that can dephosphorylate NF proteins (Guru et al., 1991; Shetty et al., 1992). Phosphate turnover occurs on NFs during axonal transport (Nixon et al., 1987). The number of phosphorylated epitopes of NF proteins at the nodes of Ranvier decreases relative to that in internodal myelinated regions (de Waegh et al., 1992; Mata et al., 1992), demonstrating the physiological significance of $\mathrm{PP}(\mathrm{s})$ in regulating the state of NF phosphorylation. Previous studies from our laboratory have reported that PP2A from both rat spinal cord and rabbit skeletal muscle can dephosphorylate NF-M/H tail domain protein after phosphorylation by cyclin-dependent kinase- 5 (Cdk5) (Veeranna et al., 1995).

The prolyl isomerase Pin 1 recognizes and induces cis-trans isomerization of pSer/Thr-Pro bonds, conferring phosphorylationdependent conformational changes relevant for protein function ( $\mathrm{Lu}$ and Zhou, 2007). The multiple repeats of the KSP motif suggest that reconfiguration of the NF-M/H may involve peptidylprolyl isomerization by Pin1, which has a specificity for phos- 
phorylated S/T-P dipeptides (Yaffe et al., 1997). Recently, we have shown that Pin 1 regulates the oxidative stress-induced phosphorylation of NF-H by prolinedirected kinases such as Cdk5, mitogenactivated protein kinase (MAPK), and c-Jun N-terminal protein kinase 3 (JNK3) (Rudrabhatla et al., 2008).

In this study, we show that PP2A expression is robust in neuronal cell bodies, and inhibition of its activity results in aberrant and hyperphosphorylation of NF on S/T-P residues. Inhibition of Pin1 inhibits okadaic acid (OA)-induced aberrant hyperphosphorylation of NF/M-H in the cell bodies and rescues the general anterograde transport of NF in OA- and fostriecin (Fos)-treated neurons. Furthermore, inhibition of Pin 1 inhibits OA- and Fos-induced neuronal cell death. We also show that Pin 1 can directly modulate the NF dephosphorylation mediated by PP2A, independent of JNK, extracellular signal-regulated kinase (ERK), and Cdk5 pathways.

\section{Materials and Methods}

Materials. We obtained the following antibodies commercially: polyclonal rabbit and goat PP2A antibodies (Santa Cruz Biotechnology), mouse monoclonal PP2A antibodies (Millipore), monoclonal antibodies to $\beta$-actin and $\beta$-tubulin (Sigma), and SMI31, SMI32, and SMI34 against phospho-S/T-P epitopes of NF$\mathrm{M} / \mathrm{H}$ tail domain (Covance). The RT97 monoclonal antibody clone was a kind gift from Dr. Brian Anderton (Institute of Psychiatry, London, UK). The protein phosphatase inhibitors OA, microcystin LR, Fos, and cyclosporine A (cyA) were purchased from Calbiochem. All cell culture reagents were purchased from Invitrogen.

Human $A D$ and ALS spinal cord. Closely matched, age and postmortem time, control, and ALS-affected spinal cord tissues were obtained from the National Institute of Child Health and Human Development (NICHD) Brain and Tissue Bank (Bethesda, MD). The ALS spinal cord tissue corresponds to lumbar region (35-60 years). The spinal cord tissue from controls comprise non-neurological disease (atherosclerotic cardiovascular disease or multiple injuries). Closely matched, age and postmortem time, control, and $\mathrm{AD}$-affected brain tissue, frontal cortex (66-86 years), were obtained from the Harvard University Brain Resource Center (Boston, MA). Frozen human tissue was used in accordance with the National Institutes of Health guidelines.

Primary neuronal cultures and treatment with phosphatase inhibitors. Primary cortical neurons were established from embryonic day 18 (E18) Sprague Dawley rat embryos (Charles River Laboratories). An 18-d-old timed pregnant rat was killed using $\mathrm{CO}_{2}$, pups were removed and decapitated, and cortex was dissected in Hibernate-E media (Brain Bits). Dissociated cortical neurons were obtained by incubating the cortex in Earle's balanced salt solution containing $15 \mathrm{U} / \mathrm{ml}$ papain (Worthington Biochemicals) for $45 \mathrm{~min}$ at $37^{\circ} \mathrm{C}$ before triturating in Neurobasal medium containing $20 \%$ fetal bovine serum (Hyclone), DNase $(0.2 \mathrm{mg} / \mathrm{ml}$ ), and $0.1 \mathrm{M} \mathrm{MgSO}_{4}$. Undissociated neurons were removed from the cell suspension by passing the cell suspension through a $40 \mu \mathrm{M}$ cell strainer (Fisher Scientific). Neurons were centrifuged at $800 \times g$ for $5 \mathrm{~min}$ at $20^{\circ} \mathrm{C}$, and the pellet was resuspended in Neurobasal medium supplemented with B27, penicillin $(100 \mathrm{U} / \mathrm{ml})$, streptomycin $(100 \mathrm{U} / \mathrm{ml})$, and L-glutamine ( $0.5 \mathrm{~mm}$; Invitrogen). Neurons were then plated at a density of 150,000 cells $/ \mathrm{ml}$ on circular glass coverslips and six-well tissue culture dishes, coated with poly-L-lysine ( $50 \mu \mathrm{g} / \mathrm{ml}$; Sigma), and incubated in a humidified atmosphere containing $5 \% \mathrm{CO}_{2} / 95 \% \mathrm{O}_{2}$ at $37^{\circ} \mathrm{C}$. The following $\mathrm{PP}$ inhibitors, OA, microcystin LR, Fos, and cyclosporine A, were added to the $7 \mathrm{~d}$ in culture (DIC) neurons.

Preparation of the NF proteins. NF proteins were prepared as described by Tokutake et al. (1983) with some modifications, as follows. Rat spinal cords and sciatic nerve were immediately washed thoroughly in ice-cold buffer after dissection in a buffer A composed of $20 \mathrm{~mm}$ Tris- $\mathrm{HCl}$ buffer, pH 6.8, containing 1 mm each EDTA, EGTA, and DTT and $100 \mathrm{~mm} \mathrm{NaCl}$ to remove blood clots and meninges. Tissues were homogenized in the same buffer $(1: 5 \mathrm{w} / \mathrm{v})$ containing $0.2 \mathrm{~mm}$ phenylmethylsulfonyl fluoride, leupeptin $(5 \mu \mathrm{g} / \mathrm{ml})$, and $1 \%$ Triton X-100. The homogenate was centri- 

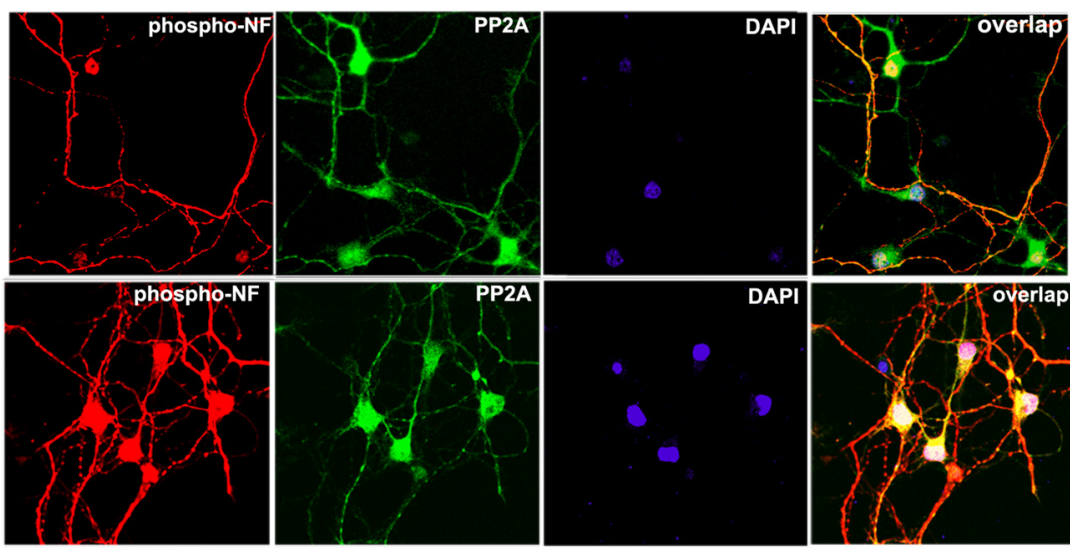

Figure 2. Colocalization of PP2A and phospho-NF in neuronal perikarya in OA-treated cortical neurons. Colocalization of PP2A and phospho-NF in the nontreated (top; NT) and OA-treated (bottom) neurons. The E18 dissociated rat cortical neurons were cultured in vitro for $6 \mathrm{~d}$, treated with $\mathrm{OA}$, and subjected to immunofluorescence. The phospho-NF was visualized using the mouse phospho-NF-M/H monoclonal antibody SMI31 (red), and PP2A was visualized using goat polyclonal antibody (green). Scale bar, 10 $\mu \mathrm{m}$.

A
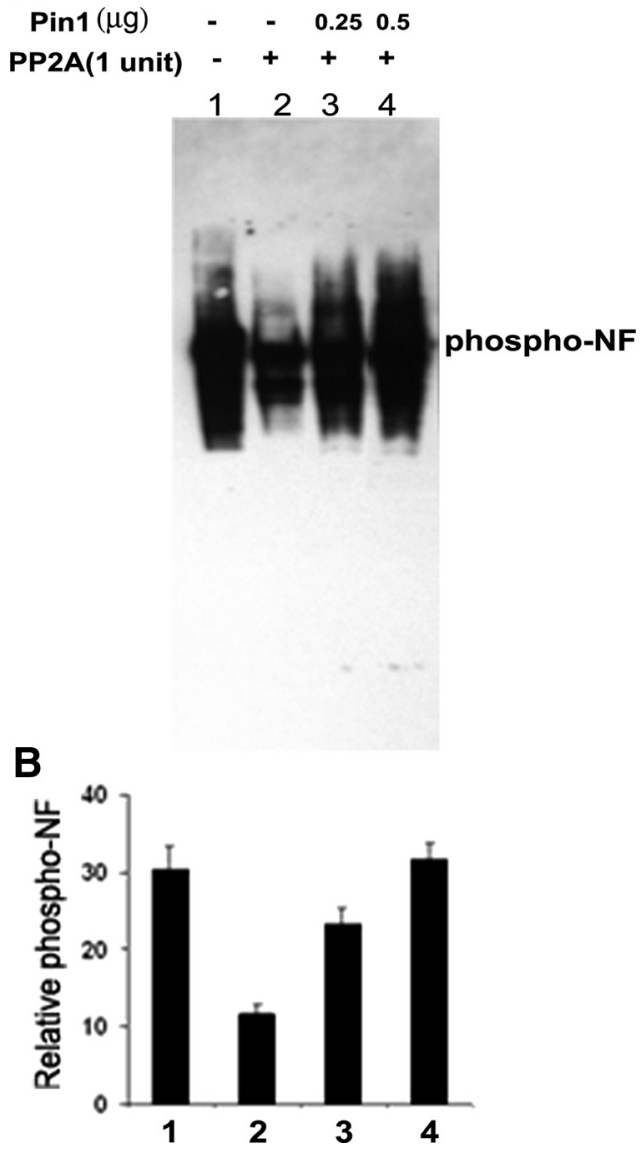

Figure 3. Dephosphorylation of NF by PP2A is inhibited by addition of Pin1 in vitro. $A, N F$ triplet (NF-H/M/L) proteins were prepared from rat spinal cord and sciatic nerve as described in Material and Methods and was subjected to dephosphorylation with $1 \mathrm{U}$ of PP2A (lane 2). The effect of Pin1 on NF-H dephosphorylation was tested by preincubating $2.5 \mu \mathrm{g}$ of NF-triplet protein with GST-Pin $1(0.25$ and $0.5 \mu \mathrm{g}$; lanes $3-4)$ at $30^{\circ} \mathrm{C}$ for $10 \mathrm{~min}$, followed by addition of $1 \mathrm{U}$ of PP2A. Reaction mixtures were incubated at $30^{\circ} \mathrm{C}$ for $30 \mathrm{~min}$. Reactions were terminated by addition of SDS loading buffer, and proteins were analyzed by $4-20 \%$ SDS-PAGE. Blots were probed with monoclonal antibodies for phosphorylated NF-H (RT97). Data show the effect of Pin 1 on NF-H dephosphorylation. PP2A dephosphorylates NF (lane 2). Addition of Pin 1 prevents NF dephosphorylation in a dose-dependent manner [lane 3 ( $0.25 \mu \mathrm{g}$ of Pin 1$)$; lane 4 (0.5 $\mu \mathrm{g}$ of Pin1)]. $\boldsymbol{B}$, Densitometry analyses of phospho-NF obtained from $\boldsymbol{A}$.
NT

fuged at $20,000 \times g$ at $4^{\circ} \mathrm{C}$ for $45 \mathrm{~min}$. The pellet was resuspended in the same buffer $\mathrm{A}$ containing $1 \mathrm{M}$ sucrose (buffer B) and centrifuged at $20,000 \times g$ for $30 \mathrm{~min}$. The floating myelin and supernatant were discarded. The pellet was resuspended in buffer $B$ and centrifuged as above. These steps were repeated four more times, and the final pellet obtained in the last step is called the NF preparation.

Dephosphorylation of NF proteins. The dephosphorylation of the NF proteins by PP2A was performed as described previously (Veeranna et al., 1995). In brief, $2 \mu \mathrm{g}$ of NF preparation was dephosphorylated with 1 unit of PP2A (Millipore) in a PP2A buffer $(20 \mathrm{~mm}$ HEPES, pH 7.0, 1 mм DTT, 1 mm $\mathrm{MnCl}_{2}, 100$ $\mu \mathrm{g} / \mathrm{ml} \mathrm{BSA}$, and $50 \mu \mathrm{M}$ leupeptin) for $30 \mathrm{~min}$. The dephosphorylation was confirmed by Western blot analysis with phospho-NF antibodies (SMI31/RT97).

Expression and purification of the Pin1 protein. Wild-type Pin1 was cloned into pGEX$5 \mathrm{X}-1$ obtained from GE Healthcare for glutathione $S$-transferase (GST) expression studies. The pGEX recombinant plasmid containing Pin1 was expressed and purified as described previously (Rudrabhatla et al., 2008).

Plasmids. Dominant-negative Pin 1 was produced by making a point mutation to produce an alanine at serine 16, using the QuikChange mutagenesis kit (Stratagene) according to the instructions of the manufacturer. Dominant-negative (DN) Pin1 was cloned as a green fluorescent protein (GFP) fusion protein of Pin1 in pCEFL-GFP vector. This was a kind gift from Dr. Silvio Gutkind (National Institute of Dental and Craniofacial Research, National Institutes of Health, Bethesda, MD). The NF-H was constructed as enhanced GFP (EGFP) fusion. The NF-H tail domain with $52 \mathrm{~S}$ /T-P repeats is cloned in pCDNA 3.1 vector for transfection studies.

Pin1 short interfering RNA. Using the HiPerformance Design Algorithm, synthetic 21-mer short interfering (siRNA) was designed and synthesized (Qiagen). Pin 1 siRNA (silencing) sense and antisense sequences were as follows: $5^{\prime}$-r(GCUCAGGCCGAGUGUACUA)dTdT-3' and 5' r(UAGUACACUCGGCCUGAGC)dTdT-3', respectively. All Stars negative control siRNA, a scrambled, nonsilencing control siRNA, was obtained (Qiagen). Sense and antisense sequence for nonsilencing siRNA were as follows: $5^{\prime}$-r(UUCUCCGAACGUGUCACGU)d(TT)- $3^{\prime}$ and $5^{\prime}$ r(ACGUGACACGUUCGGAGAA)d(TT)-3', respectively. To ensure the absence of possible complementary binding sites in mammalian genomes, the siRNA sequences were extensively checked against the GenBank database using the Smith-Waterman algorithm. This strategy was used to exclude significant sequence homology within the genomes of mammalian species, which may interfere with the target specificity of the siRNA and contribute to unwanted off-target effects in later experiments. The sense and antisense strands were annealed to create the double-stranded siRNA at a $20 \mu \mathrm{M}$ concentration. Control siRNA and Pin 1 siRNA were dissolved in suspension buffer to obtain a $20 \mu \mathrm{M}$ solution and then heated at $90^{\circ} \mathrm{C}$ for $1 \mathrm{~min}$. The final transfection step was preceded by a $60 \mathrm{~min}$ incubation at $37^{\circ} \mathrm{C}$. Delivery of siRNA was performed as described previously (Kesavapany et al., 2007; Rudrabhatla et al., 2008).

Electrophoresis and Western blotting. Electrophoresis and Western blotting were performed as described previously (Rudrabhatla et al., 2008).

Immunocytochemistry of primary cortical neurons. Cortical neurons fixed in $4 \%$ paraformaldehyde were permeabilized for $20 \mathrm{~min}$ in $0.2 \%$ Triton X-100, blocked in 5\% fetal calf serum in PBS containing $1 \%$ Triton X-100 for $1 \mathrm{~h}$, and incubated with primary antibodies (diluted in blocking buffer) against phospho-specific monoclonal antibody against NF (SMI31) or with polyclonal antibodies to Pin1 or PP2A (Cell Signaling Technology) for overnight at $4^{\circ} \mathrm{C}$. After six washes in PBS, the neurons were incubated with anti-rabbit (Alexa 488) and anti-mouse (Alexa 
594) secondary antibodies (Invitrogen). Secondary antibodies were diluted in the same buffer as the primary antibodies and incubated for $2 \mathrm{~h}$ at room temperature. Cells were washed and mounted on the coverslips, and images were captured with an oil-immersion $63 \times$ objective on a Zeiss LSM510 using LSM Image Software. The images were analyzed using a TCS software program on an Axiovert $200 \mathrm{M}$ microscope (Zeiss).

In situ cell death detection (terminal deoxynucleotidyl transferase-mediated biotinylated UTP nick end labeling assay). In situ cell death detection was performed as described previously (Rudrabhatla et al., 2008). In brief, after primary cortical neurons were cultured and treated, cells were fixed and prepared for terminal deoxynucleotidyl transferase-mediated biotinylated UTP nick end labeling (TUNEL) staining according to the instructions of the manufacturer (In Situ Cell Death Detection kit; Roche Diagnostics). Nuclei were counterstained using 4' 6-diamidino-2-phenylindole (DAPI). TUNEL staining fluorescent images were captured with a Zeiss LSM510 laserscanning confocal microscope. Cell counts were performed as described in figure legends.

Protein phosphatase PP2A activity measurements. Closely matched, age and postmortem time, control, and ALS-affected spinal cord tissues were obtained from the NICHD Brain and Tissue Bank. Homogenates were prepared in duplicate from three ALS and control brains, and four assays were performed with each homogenate. Mean values and SDs were calculated. The amount of released phosphate was determined by measuring the absorbance of a malachite green:phosphate complex at 650 $\mathrm{nm}$. Spinal cord extracts of age-matched control and ALS samples were prepared with a Te-

flon homogenizer (40 strokes at $100 \mathrm{rpm})$ in $1 \times$ TBS and $1 \%(\mathrm{v} / \mathrm{v})$ Triton $\mathrm{X}-100$ in the presence of protease inhibitors (CompleteTM with EDTA; Roche Diagnostics). Phosphatase assays were performed with these extracts using the PP2A immunoprecipitation phosphatase assay kit (catalog number 17-313; Millipore) (Guan et al., 2007). Release of phosphate from a chemically synthesized phospho-peptide (K-R-pT-I-R-R, in which $\mathrm{pT}$ is phospho-threonine), which is a substrate for PP2A measured over a period of $30 \mathrm{~min}$.

Statistics. Each experiment was repeated at least four times. The data were expressed as the means $\pm \mathrm{SD}$. Student's $t$ tests were used to compare the effects of all treatments. The differences were considered statistically significant as ${ }^{\star} p<0.01$ and ${ }^{* *} p<0.001$.

\section{Results}

PP2A regulates topographic phosphorylation of NFs

Four phosphatase inhibitors were used in the present study: (1) $\mathrm{OA}$, a marine sponge toxin first isolated from a genus of sponges, Halichondria, reported to directly inhibit the catalytic subunits of multiple phosphatases; (2) mLR, a potent and selective protein phosphatase 1 and $2 \mathrm{~A}$ inhibitor, hepatotoxin isolated from strains of the blue-green algae Microcystis aeruginosa; (3) Fos is an antitumor antibiotic with inhibitory activity against serine/threonine PP1 and PP2A and is highly selective for PP2A; (4) cyclosporine A, a PP2B (calcineurin) specific inhibitor. To study the involvement of protein phosphatases on perikaryal phosphorylation of NFs, we began with the PP1/PP2A inhibitor okadaic acid $(0.25 \mu \mathrm{M})$. The E18 7 DIC dissociated rat cortical neurons were stained with phospho-NF antibodies. We used SMI31, a mono-
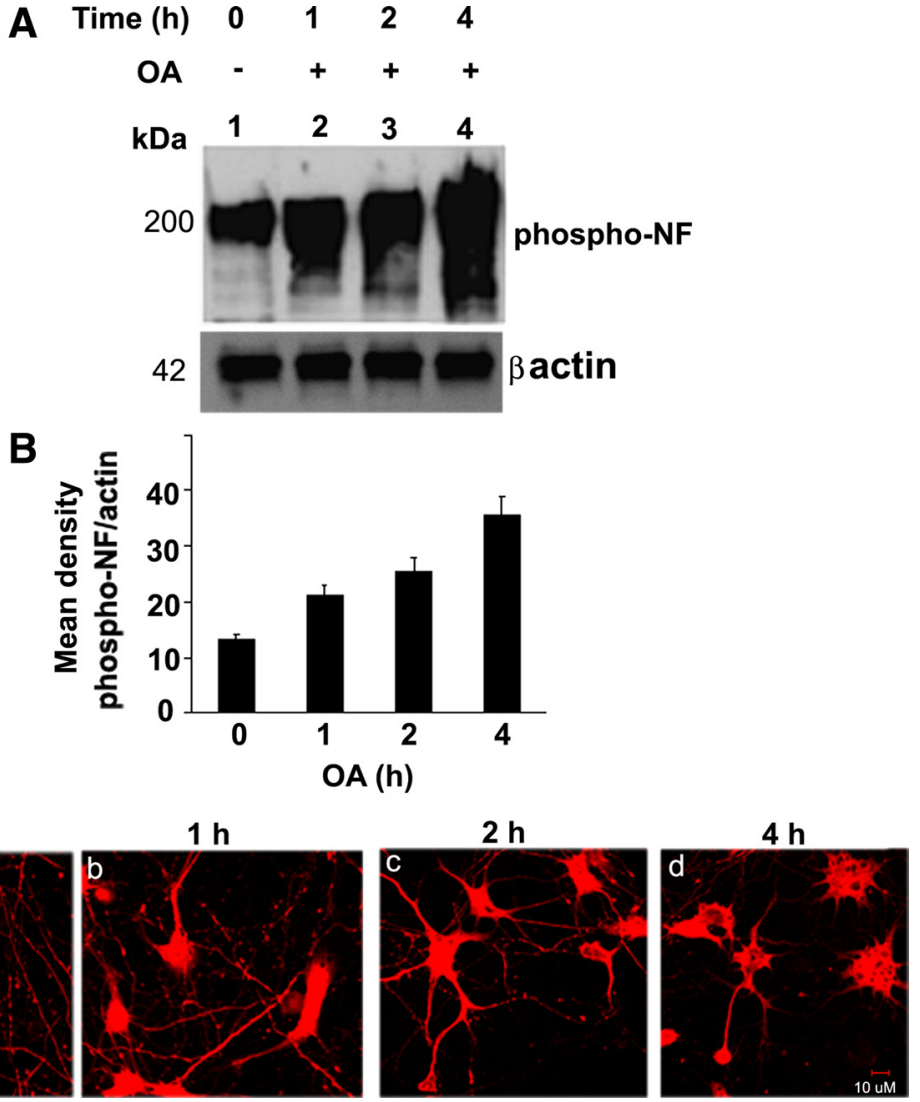

Figure 4. $\quad 0 A$ increases the NF phosphorylation in a time-dependent manner. $\boldsymbol{A}$, The $7 \mathrm{DIC}$ cortical neurons were treated with $0 \mathrm{~A}$ . Mean density, Phospho-NF/actin is plotted on the $y$-axis. C, Five DIC neurons were treated with OA for 1,2 , and 4 h, and immunofluorescence was performed with SMI31 antibodies. In normal neurons, SMI31 is stained in axonal compartment (a). The phospho-NF accumulates in cell bodies in a time-dependent manner. Scale bar, $10 \mu \mathrm{m}$.

clonal antibody that specifically detects phosphorylated Ser/ThrPro repeats of NF-M/H tail domain. Figure $1 A$ represents the NF-M and NF-H tail domain comprising multiple KSP repeats (rat NF-H, 52 KSP repeats). The antibodies used in this study pertaining to phosphorylated and non-phospho-NF antibodies is also shown (SMI31, SMI34, RT97, and SMI32) in Figure $1 A$. Figure $1 \mathrm{Ba}$ shows the SMI31 staining of cortical neurons under normal conditions. The phospho-NF stains only the axons and processes, and there is no staining of SMI31 in the perikarya (Fig. $1 \mathrm{Ba}$ ). When okadaic acid is added to the cortical neurons for $2.5 \mathrm{~h}$, we observed phospho-NF accumulations in the perikarya (Fig. $1 \mathrm{Bb}$ ). To confirm that PP2A is involved, we also tested the PP1/PP2A inhibitor microcystin LR $(15 \mu \mathrm{M})$, which increased perikaryal phosphorylation of NF in cortical neurons (Fig. $1 \mathrm{Bc}$ ). Also, there was a significant increase in the perikaryal hyperphosphorylation of NF with the PP2A-selective inhibitor fostriecin (1 $\mu \mathrm{M}$ ) (Fig. $1 B d$ ). We then tested the effect of the PP2B inhibitor cyA on topographic phosphorylation of NF. We used increasing concentrations of cyA, $0.5 \mu \mathrm{M}$ (Fig. 1Cb), $1 \mu \mathrm{M}$ (Fig. 1Cc), and 2.5 $\mu \mathrm{M}$ (Fig. $1 C d$ ), and detected no change in the perikaryal phosphorylation of NF compared with nontreated neurons (Fig. 1Ca). These data implicate that there was significant phospho-NF-M/H accumulations in neuronal perikarya with the PP2A inhibitors $\mathrm{OA}, \mathrm{mLR}$, and Fos but not with the PP2B inhibitor cyclosporine A. To further confirm these results, we have used SMI34 antibodies that specifically detect phospho-NF, under these experimental 
conditions. At 1:20,000 dilutions, SMI34 does not cross-react with phospho-Tau, further demonstrating the specificity of phospho-NF immunoreactivity. These results are also confirmed by using the phospho-NF-H antibody RT97. The densitometry analysis of perikaryal p-NF-M/H as detected by SMI31, SMI34, and RT97 from untreated and treated (OA, mLR, Fos, and cyA) neurons from four independent experiments is shown in Figure $1 D$. We then tested the effect of PP2A inhibitors on NF phosphorylation using the non-phospho-NF antibody SMI32. In normal neurons, there is maximal staining of SMI32 in cell bodies (supplemental Fig. 1, available at www.jneurosci.org as supplemental material). Treatment of cortical neurons with OA, mLR, and Fos decreased SMI32 (non-phospho-NF) immunoreactivity in neuronal perikarya, but cyA did not have any effect (supplemental Fig. 1, available at www.jneurosci.org as supplemental material). The densitometry analysis of perikaryal p-NF-M/H from untreated and treated neurons using SMI32 is shown in supplemental Figure $1 B$ (available at www.jneurosci.org as supplemental material).

\section{Colocalization of PP2A and phospho-NF}

To examine the cellular localization of PP2A with phospho-NF, immunocytochemical analyses were performed on dissociated E18 rat cortical neurons cultured for $7 \mathrm{~d}$ in nontreated and treated with okadaic acid. A rhodamine-conjugated secondary antibody was used to show endogenous phospho-NF expression, and Oregon green secondary antibody was used for endogenous PP2A (Fig. 2). PP2A expression is robust in the cell bodies of cortical neurons. The phospho-NF is predominantly localized in the axons in nontreated neurons (Fig. 2, top row) and in cell bodies of OA-treated cortical neurons (Fig. 2, bottom row). In the overlay image, colocalization of PP2A and phospho-NF can be seen in the cell bodies in OA-treated neurons (Fig. 2, bottom right panel).

\section{Pin 1 prevents the dephosphorylation of NF proteins by PP2A in vitro}

Tau and NF-H/M are the physiological substrates of PP2A. Previous reports have shown that Pin1 modulates the dephosphorylation of Tau at $\operatorname{Thr}(231)$ by PP2A. Rat NF-H has 52 SP repeats in the tail domain in tandem. Therefore, we wanted to study the effect of Pin 1 in NF tail domain dephosphorylation by PP2A. The close relationship between phosphorylation and NF structure and function suggests that Pin 1 could play a direct role in modulating NF function by influencing phosphorylation/dephosphorylation. We first tested the effect of Pin 1 on the ability of PP2A to dephosphorylate the endogenously phosphorylated NF. We prepared rat NF triplet proteins from spinal cord and sciatic nerve. NF proteins are highly phosphorylated in vivo and form an excellent substrate to study dephosphorylation. We purified recombinant human Pin 1 as a GST fusion protein from Escherichia coli. Purified NF proteins were dephosphorylated with PP2A in the presence or absence of increasing amounts of GST-Pin1, and the NF dephosphorylation was assayed by Western blotting with a phospho-NF-H antibody (RT97). RT97 is a monoclonal antibody that recognizes the phosphorylated S/T-P residues of NF-H. The results show that PP2A was able to dephosphorylate endogenously phosphorylated NF-H (Fig. 3A, lane 1, endogenous phospho-NF-H; lane 2, PP2A-treated NF-H). The addition of GST-Pin1 inhibited NF-H dephosphorylation in a dose-dependent manner (Fig. 3, lanes 3, 4). GST alone did not have an effect on NF dephosphorylation by PP2A (data not shown). These results suggest that the Pin 1 reduces dephosphorylation of the NF
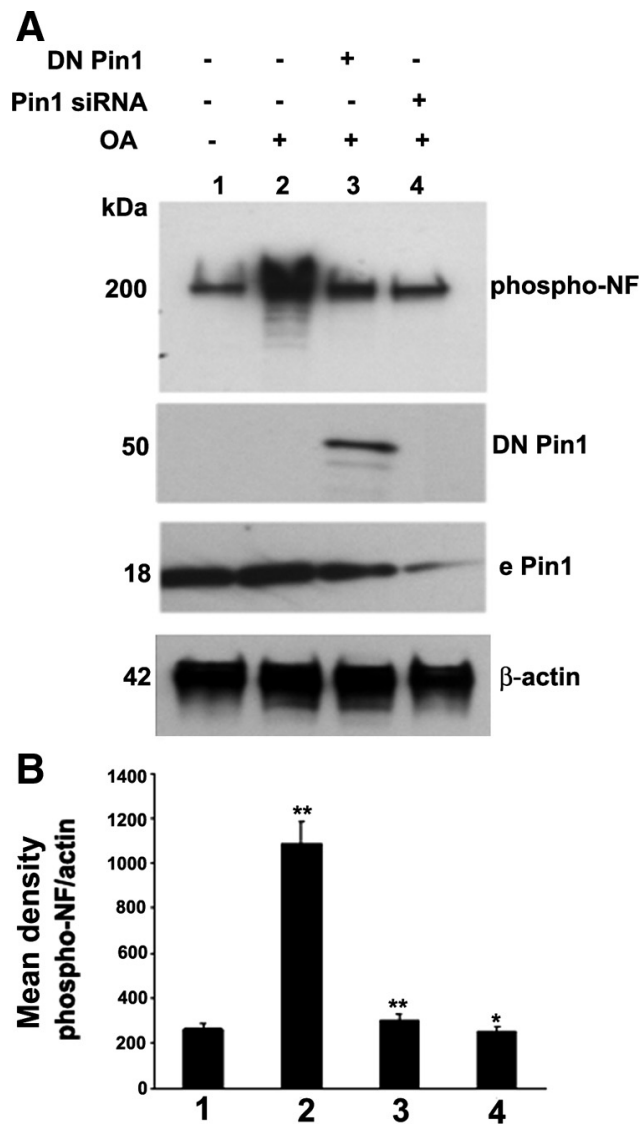

Figure 5. Pin1 expression and activity is critical toward $O A$-induced aberrant hyperphosphorylation of NF. $A$, Cortical neurons were subjected to treatment with $0 \mathrm{~A}(0.2 \mu \mathrm{m}$ for $2.5 \mathrm{~h})$, and Western blot analysis was performed with phospho-NF-M/H (SMI31) staining. The OA-induced hyperphosphorylation of NF is inhibited by knockdown of Pin1 by Pin1 siRNA and DN Pin1transfected neurons. Lanes 1 and 2, Control scrambled siRNA-transfected neurons. Lanes 2-4, OA-treated neurons. Lane 3, Pin1 siRNA-transfected neurons. Lane 4, DN Pin1-transfected neurons. The transfected Pin 1 is a GFP fusion protein and migrates at $50 \mathrm{kDa}$, at which the endogenous Pin1 (e Pin1) is $18 \mathrm{kDa}$. $\boldsymbol{B}$, Densitometry analysis of phospho-NF immunoreactivity obtained from $\boldsymbol{A}$. Mean density, Phospho-NF/actin is plotted on the $y$-axis. ${ }^{*} p<0.01$ and ${ }^{* *} p<0.001$ of phospho-NF-M/H relative to nontreated neurons.

proteins by inhibiting PP2A activity. Figure $3 B$ represents the effect of Pin 1 on NF dephosphorylation with the data obtained from three separate experiments.

\section{Pin1 modulates NF dephosphorylation in vivo}

The studies described above show that Pin 1 prevents dephosphorylation of NF in vitro. We next examined whether Pin 1 modulates NF dephosphorylation in vivo. Treatment of 7 DIC cortical neurons with $0.25 \mu \mathrm{M}$ OA increased the phosphorylation of NF in a time-dependent manner (Fig. 4). Maximal NF phosphorylation was observed $4 \mathrm{~h}$ after $\mathrm{OA}$ treatment (Fig. $4 A$ ). Figure $4 B$ represents the densitometry analysis of OA-induced phosphorylation of NF. The cortical neurons treated with OA showed accumulation of phospho-NF-M/H in cell bodies in a time-dependent manner. At $4 \mathrm{~h}$ after OA treatment, cortical neurons showed maximum accumulation of phospho-NF in cell bodies (Fig. 4C).

If Pin 1 acts by preventing the dephosphorylation of NF, then transfection of DN Pin 1 should inhibit the OA-induced increase in NF phosphorylation. Transfection of DN Pin1 inhibited the OA-induced phospho-NF accumulations (Fig. 5A). The endogenous Pin 1 migrates at $18 \mathrm{kDa}$, whereas transfected GFP DN Pin 1 migrates at $50 \mathrm{kDa}$. In addition, knockdown of Pin 1 by Pin 1 
siRNA inhibited the increase in phospho-NF accumulations by OA. Knockdown of Pin 1 by Pin 1 siRNA reduced significant levels of Pin 1 expression (Fig. 5A). Figure $5 B$ represents the densitometry analysis of $\mathrm{OA}$-induced phosphorylation of NF (NF$\mathrm{M} / \mathrm{H}$ ) by inhibition of Pin 1 activity. These results suggest that Pin 1 prevents dephosphorylation of NF-M/H in vivo, in cortical neurons.

\section{OA-induced aberrant perikaryal phospho-NF accumulations are inhibited by transfection of DN Pin 1 and Pin 1 siRNA in cortical neurons} The PP2A activity is downregulated in AD brain (Sontag et al., 2004). In a cellular model of primary cortical cultures, we used OA to inhibit PP2A. Under normal conditions, the cortical neurons show phospho-NF staining in the axonal compartment (Fig. 6Aa). SMI31 antibodies do not stain phospho-NF-M/H in the neuronal perikarya in normal neurons. However, the cross reactivity of SMI31 antibodies with nuclei is reported (Schilling et al., 1989). The nuclear localization of SMI31 is attributable to the association of phosphorylated histones with nuclear components (Weigum et al., 2003). Pin1 is present in both axons and cell bodies (Fig. $6 A b)$. Pin 1 colocalizes with phospho-NF only in the axons (Fig. 6Ac). The cortical neurons treated with OA show phospho-NF accumulations in the perikarya (Fig. $6 A d$ ), and Pin 1 colocalizes with the phospho-NF in the cell bodies (Fig. 6Af). Knockdown of Pin1 with Pin 1 siRNA shows the reduction of Pin 1 staining by $80 \%$ compared with control scrambled siRNA-transfected neurons (Fig. 6Ah). Pin1 siRNA-transfected neurons show the phospho-NF staining as observed in control neurons (Fig. 6Ag$A i)$. For comparison purposes, we captured neurons that show both Pin 1 siRNA-transfected neurons (indicated in yellow arrows) and nontransfected neurons (white arrows). It should be noted that only the Pin 1 siRNA-transfected neurons show the reduction in perikaryal phosphorylation of NF (Fig. 6Ag-Ai). The quantitation of perikaryal p-NF-M/H from untreated and OA-treated neurons from four independent experiments is shown in Figure $6 \mathrm{~B}$. Figure $6 C$ shows the effect of Pin 1 on perikaryal phosphorylation of NF-M/H by treatment of cortical cultures with Fos. These results suggest that the treatment of cultured neuronal cells with OA induces perikaryal accumulation of the NF phospho-epitopes that are normally confined to axons, and these effects are prevented by inhibition of Pin 1 .

DN Pin 1 inhibits the Pin 1 activity without changing Pin 1 protein levels. Transfection of cortical neurons with GFP-DN Pin1 inhibited the OA-induced hyperphosphorylation of NF in the cell body (Fig. 7). Two neurons are captured, with and without GFP-DN Pin1 transfection. In OA-treated neurons, the densi- tometry analysis of the relative perikaryal phospho-NF in GF$\mathrm{P}-\mathrm{DN}$ Pin1-transfected neurons is reduced by $\sim 3.5$-fold compared with nontransfected neurons. These results further demonstrate that inhibition of Pin1 levels (Pin1 siRNA) or Pin1 activity (DN Pin1) inhibits OA-induced aberrant perikaryal hyperphosphorylation of neurons. These results show that Pin1 prevents the dephosphorylation of NF in vivo.

Pin1 directly modulates PP2A-mediated dephosphorylation of NF, independent of ERK, JNK, and Cdk5 pathways There are several reports that Pin 1 modulates PP2A-mediated dephosphorylation of target proteins (Zhou et al., 2000). Inhibition of PP2A by OA may activate JNK. To determine whether aberrant hyperphosphorylation of NF in OA-treated neurons in response to Pin 1 knockdown is a consequence of kinase activation or a direct consequence of PP2A-mediated dephosphorylation of NF, we tested the NF phosphorylation with kinase 

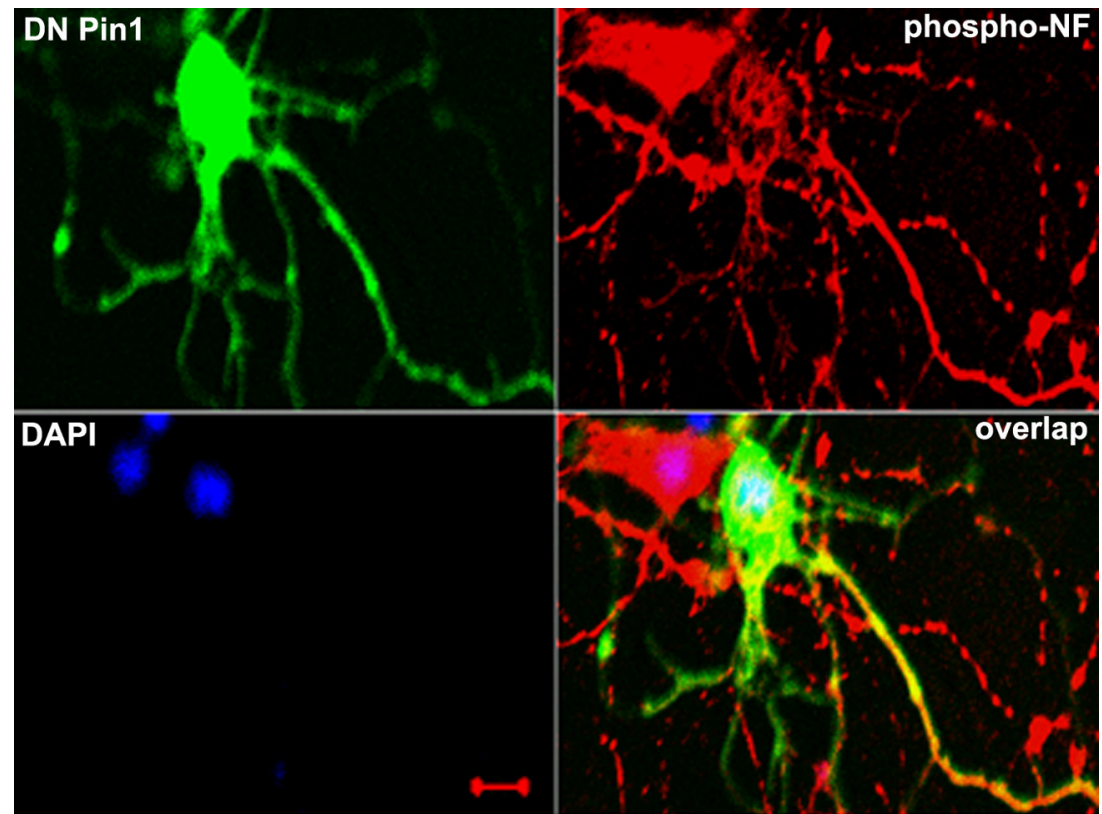

Figure 7. OA-mediated increase in phosphorylated NF is reduced by overexpression of DN Pin1. Five-day-old cortical neurons were transfected with GFP-DN Pin1 and after $24 \mathrm{~h}$ were treated with $0.25 \mu \mathrm{M} \mathrm{OA}$ for $2.5 \mathrm{~h}$. Neurons were immunostained, phospho-NF was detected using SMI31 (red), and DN Pin1 was detected through expression of GFP. Note that only neurons that show DN Pin1 expression exhibited significant reduction of phosphorylated NF in the cell body. Scale bar, $20 \mu \mathrm{m}$.

\section{Roscovitine SP600125 PD98059} OA
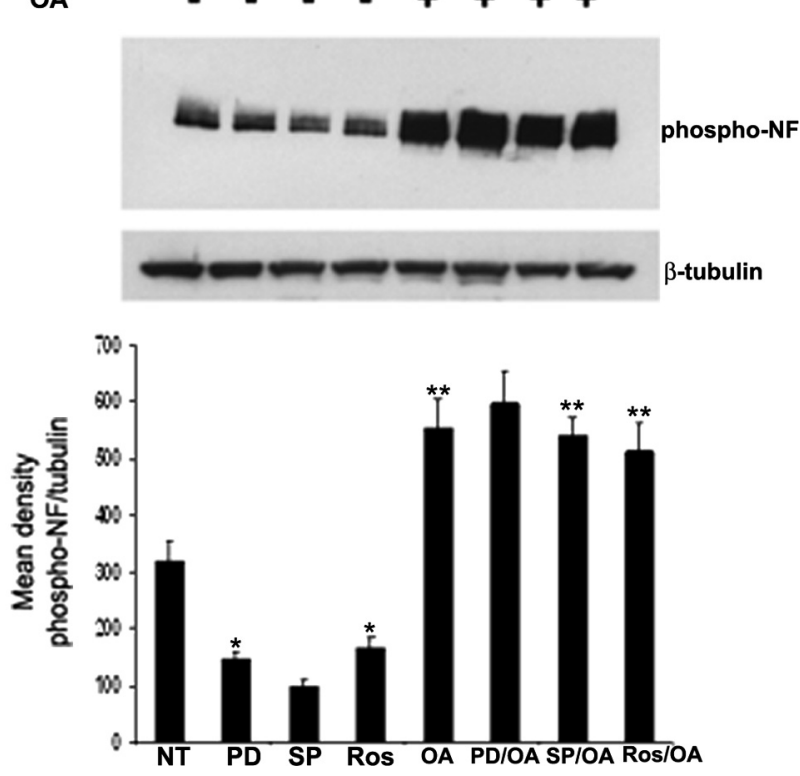

Figure 8. Pin1 modulates PP2A-mediated dephosphorylation of NF independent of ERK, JNK, and Cdk5 pathways. Seven DIC neurons were treated with PD98059 (ERK inhibitor; PD; lanes 2, 6), SP600125 (JNKinhibitor; SP; lanes 3, 7), and roscovitine (Cdk5 inhibitor; Ros; lanes 4, 8) for $1 \mathrm{~h}$. The neurons were then subjected to treatment with $O A$ (lanes $5-8$ ) for $2 \mathrm{~h}$. The phospho-NF was detected by SMI31 antibodies. The equal loading of the protein was confirmed by Western blot analysis with monoclonal $\beta$-tubulin antibodies. The bottom shows the densitometry analysis of mean phospho-NF/tubulin obtained from the top. ${ }^{*} p<0.01$ and ${ }^{* *} p<$ 0.001 of phospho-NF-M/H intensity relative to nontreated neurons (NT). inhibitors (JNK, ERK, and roscovitine) before the addition of PP2A inhibitor. Nontreated and kinase inhibitor treatment of cortical neurons with the JNK inhibitor SP600125 (anthra[1,9-cd]pyrazol$6(2 \mathrm{H})$-one), the ERK inhibitor PD98059 [2-(2-amino-3-methyoxyphenyl)-4 H-1benzopyran-4-one], or the C $\mathrm{dk} 5$ inhibitor roscovitine before the addition of OA did not change the levels of phospho-NF accumulation after the treatment of neurons with $\mathrm{OA}$, suggesting that the aberrant phosphorylation of NF mediated by PP $2 \mathrm{~A}$ is not attributable to the activation of JNK/ERK/Cdk5 kinase pathways (Fig. 8, top). These results suggest that Pin 1 directly modulates $\mathrm{PP} 2 \mathrm{~A}$-mediated hyperphosphorylation of NF independent of JNK, ERK, or Cdk5 cascades (Fig. 8, bottom). These results corroborate the in vitro studies (Fig. 3) that Pin 1 prevents the dephosphorylation of NFs.

\section{Pin1 modulates the NF transport in OA-treated neurons}

Phosphorylation has long been considered to regulate NF interaction and axonal transport, and, in turn, influences axonal stability and their maturation. Shea et al. (2004) have shown that NF phosphorylation modulates NF dynamics and axonal transport. The above studies show the aberrant distribution of phospho-NF in OAtreated neurons. This prompted us to study the NF axonal transport under these conditions. We transfected GFP-NF-H in primary cortical neurons for $24 \mathrm{~h}$ to allow the accumulation of GFP-tagged subunits. Previous studies have demonstrated that 18-24 h were required for transfected cells to accumulate sufficient GFP-NF-M for visualization (Yabe et al., 1999). Cultures were treated for the final $2 \mathrm{~h}$ with OA or Fos. Transfection of GFP-NF-H resulted in the transport of exogenously expressed NF-H into the axons (Fig. $9 a-c$ ). We performed staining with polyclonal Tuj1 (red), a neuronal marker to confirm the neuronal identity. When cortical neurons are treated with OA for $2 \mathrm{~h}$, $\mathrm{NF}$ translocation is disrupted as observed by the GFP-NF-H in the cell bodies and proximal axons only, and NF proteins are not transported until the distal part of axons (Fig. 9d-f). Similar results were observed by treatment of cortical neurons with Fos (Fig. $9 g-i$ ). For inhibition of PP2A with OA or Fos, GFP-NF-H was not targeted into the axonal processes of transfected cells and thus reduced anterograde GFP-NF-H axonal transport (Fig. 9d-i). Then, we asked whether inhibition of Pin 1 rescues general axonal transport of GFP-NF-H in OA- and Fos-treated neurons. In Pin 1 siRNA-transfected neurons, treatment with OA retained the transport of GFP-NF-H, as observed in nontreated neurons (Fig. 9j-l). Knockdown of Pin 1 rescues the general anterograde transport of GFP-NF-H in OA-treated neurons (Fig. 9j-l) and Fos-treated neurons (Fig. $9 m-o$ ). The NF translocation is disrupted in OA-treated neurons as a result of the hyperphosphorylation of NF in the cell bodies. These results suggest that NF phosphorylation modulates the NF transport. These results indicate a possible role of Pin1 in NF dynamics. We also transfected C-terminal KSP repeat domain of NF-H (non-GFP-tagged) in primary cortical neurons for $24 \mathrm{~h}$ and performed immunofluo- 
rescence with total polyclonal NF-H antibodies. Transfected NF-H is translocated into the axonal compartment in normal neurons (supplemental Fig. $2 \mathrm{~A}$, available at www.jneurosci.org as supplemental material). When cortical neurons are treated with OA for $2 \mathrm{~h}$, NF translocation is disrupted and NF proteins are not transported until the distal part of axons (supplemental Fig. $2 \mathrm{~B}$, available at www. jneurosci.org as supplemental material). Knockdown of Pin 1 rescues the NF axonal translocation in OA-treated neurons (supplemental Fig. 2C, available at www. jneurosci.org as supplemental material). These results are consistent with previous studies (Shea et al., 2004) that show that phosphorylation of NF regulates NF transport. To determine the effect of DN Pin 1 on NF-H translocation in primary neurons, we cotransfected GFP-DN Pin1 with NF-H construct (non-GFP-tagged) and subjected to treatment with OA. The GFP-DN Pin1-transfected neurons show normal translocation of NF-H in OAtreated neurons (supplemental Fig. 2D, $1-3$, available at www.jneurosci.org as supplemental material). These results suggest that the generalized anterograde transport of GFP-NF-H defects are caused by treatment of cortical neurons with OA and Fos, and inhibition of Pin 1 rescues the normal transport of cortical neurons.

\section{OA-induced phospho-NF}

accumulations in perikarya leads to apoptosis

Hyperphosphorylation of neurofilament and Tau may underlie the cytoskeletal abnormalities and neuronal death seen in several neurodegenerative diseases, in-

cluding Alzheimer's disease (Ahlijanian et al., 2000, Kesavapany et al., 2007). Previous studies have described that hyperphosphorylation of NF in neuronal cell bodies leads to neuronal cell death (Ahlijanian et al., 2000; Rao and Nixon, 2003; Kesavapany et al., 2008). Furthermore, hyperphosphorylation of neurofilament in perikarya leads to inhibition of general anterograde transport of NF and eventually leads to cell death. To extend these findings, we asked whether hyperphosphorylation of NF in cell bodies in OAtreated neurons causes cell death. To test this possibility, we measured apoptosis by using TUNEL assay. Treatment of cortical neurons with $0.25 \mu \mathrm{M}$ OA resulted in the increase in the TUNELpositive neurons in a time-dependent manner (Fig. 10). The percentage apoptosis is gradually increased to $78 \%$ with $10 \mathrm{~h}$ OA treatment. Treatment of cortical neurons for longer times resulted in the detachment of neurons from the coverslip (data not shown).

\section{Inhibition of Pin1 rescues OA-induced apoptosis}

We next examined whether Pin 1 modulates OA-induced neuronal cell death. In normal neurons, $\sim 5 \%$ of untreated cortical neurons were TUNEL positive (basal level), and this increased to $>46 \%$ during OA treatment for $5 \mathrm{~h}$ (Fig. $11 A, B$ ). Inhibition of
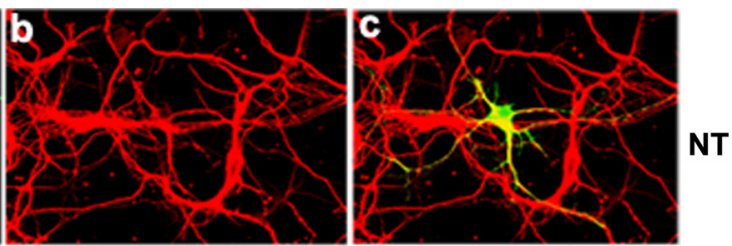

NT
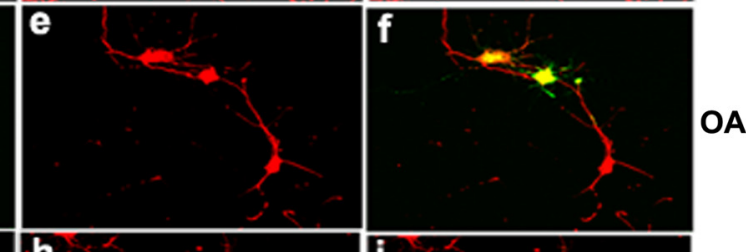

OA
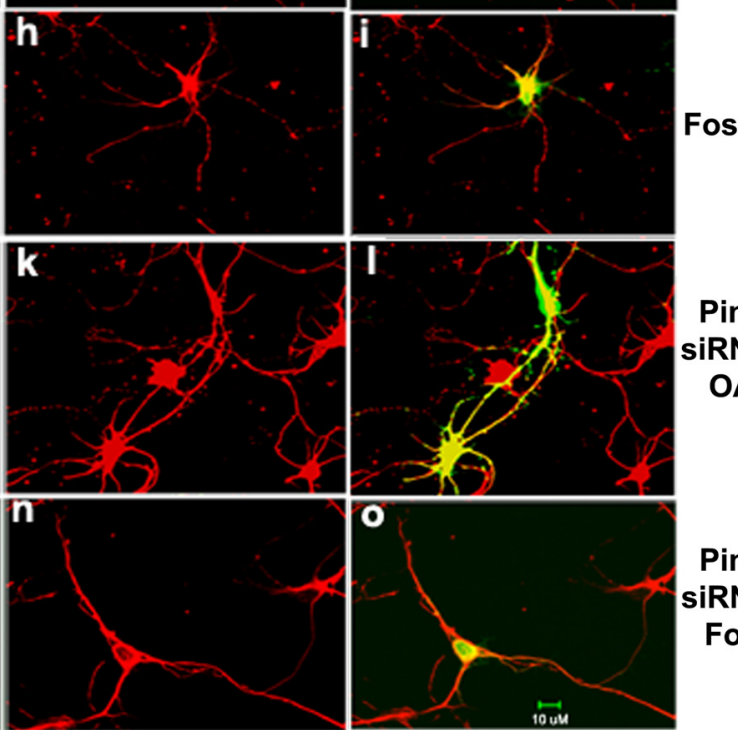

Pin1

SIRNA

OA

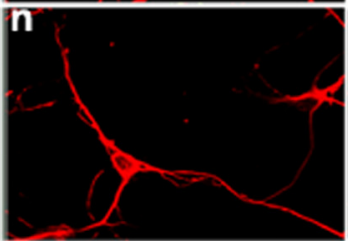

Pin1

SiRNA/

Fos

Figure 9. Pin1 modulates NF transport of OA-treated neurons. The GFP-NF-H was transfected on 5 DIC cortical neurons. After $4 \mathrm{~h}$, the NF translocation of transfected NF-H was monitored. The colocalization of GFP-NF-H-transfected neurons was observed neurons, GFP-NF-H is not translocated into axons $(\boldsymbol{g}-\boldsymbol{i})$. However, knockdown of Pin 1 rescues the normal NF translocation into the axons in OA-treated neurons $(\boldsymbol{j}-\boldsymbol{I})$ and Fos-treated neurons $(\boldsymbol{m}-\mathbf{0})$. Scale bar, $10 \mu \mathrm{m}$. NT, Nontreated.

Pin 1 by Pin 1 siRNA reduced TUNEL-positive neurons to $10 \%$, nearly comparable with nontreated neurons. Representative TUNEL images are shown, in which quantification in the bar graph represents TUNEL-positive counts from four separate experiments, in which 10 independent fields were counted (Fig. 11). Furthermore, treatment of cortical neurons with Fos increases the TUNEL-positive neurons by $38 \%$ (basal level TUNEL-positive neurons was 7\%), and inhibition of Pin1 rescues the neuronal apoptosis in Fos-treated cells (Fig. 11C). These results were further confirmed by transfecting cortical neurons with GFP-DN Pin1. Figure $11 \mathrm{D}$ shows that the GFP-DN Pin1-transfected neurons survive during OA-induced neuronal apoptosis.

\section{Downregulation of PP2A activity in ALS spinal cord and AD brain}

Aberrant accumulation of extensively phosphorylated NF proteins are observed in ALS (Hirano et al., 1984; Hirano, 1991; Wharton and Ince, 2003; Green et al., 2005; Strong et al., 2005; Xiao et al., 2006). However, PP2A activity from ALS spinal cord lysate has not been studied so far. To determine whether PP2A activity is altered in ALS, we measured PP2A activity by a colorimetric assay. Homogenates were obtained from lumbar spinal 


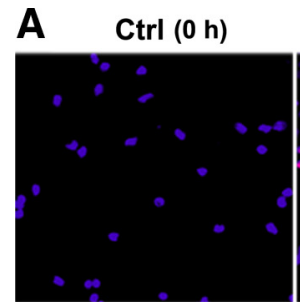

$\mathbf{7 \%}$
$2.5 \mathrm{~h}$

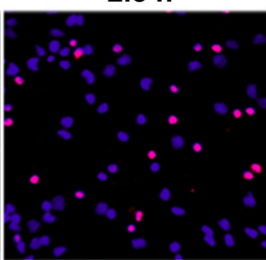

$28 \%$

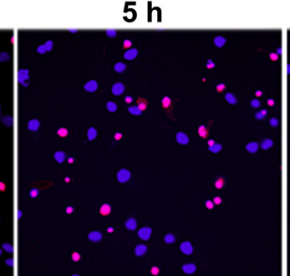

$43 \%$

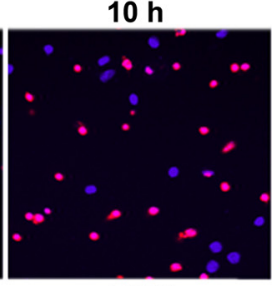

$78 \%$

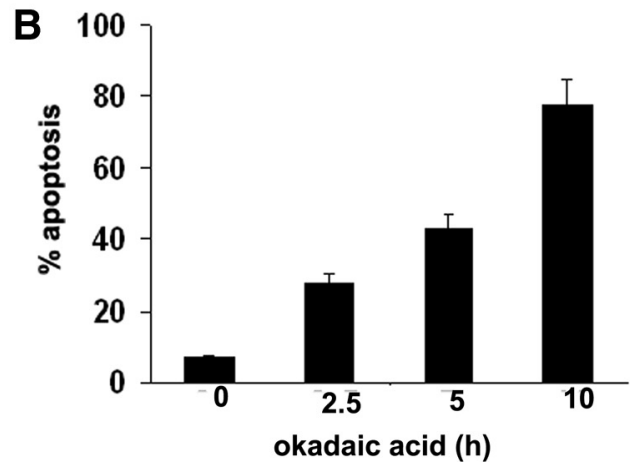

Figure 10. Inhibition of PP2A by OA increases apoptosis in a time-dependent manner. The presence of apoptotic neurons examined by TUNEL-tetramethylrhodamine red staining in $7 \mathrm{DIC}$ cortical neurons. Nuclei were counterstained using DAPI. TUNELpositive cells were increased during treatment of cortical neurons with $0 \mathrm{~A}$ in a time-dependent manner. $A$, The neuronal death is increased by nearly $28 \%(2.5 \mathrm{~h}), 43 \%(5 \mathrm{~h})$, and $78 \%$ (10\%) after treatment with $0.25 \mu \mathrm{M} \mathrm{OA.B}$, The quantization in the bar graph represents TUNEL-positive counts from four separate experiments, in which 14 independent fields were counted. Ctrl, Control.

cords of matched controls and ALS, immunoprecipitated with PP2A antibodies. The activities were determined in triplicate samples, by using phospho-peptide substrate that can be dephosphorylated by PP2A. Dephosphorylation of the peptide was determined by measuring the release of phosphate using a quantitative malachite-based colorimetric assay. The results show that PP2A activity is reduced in lumbar ALS spinal cord lysate $(1520 \pm 110 \mathrm{pmol} / \mathrm{min})$ compared with matched controls $(2611 \pm 180 \mathrm{pmol} / \mathrm{min})$. We measured the PP2A activity from adult $\mathrm{AD}$ brains and found that PP2A activity is downregulated in AD brain (997 $\pm 89 \mathrm{pmol} / \mathrm{min}$ ) compared with matched controls (2016 $\pm 199 \mathrm{pmol} / \mathrm{min})$.

\section{Discussion}

Aberrant phosphorylation of NF-M/H causes the NF to form aggregates of phospho-NF-M/H in neuronal perikarya in $\mathrm{AD}$ and ALS. Our understanding of this phenomenon has improved over the past decade, although the mechanism underlying the hyperphosphorylation of NF is still unclear (Sternberger et al., 1985; Goldman and Yen, 1986; Lee et al., 1988; Manetto et al., 1988; Veeranna et al., 1998; Grant and Pant, 2000; Zheng et al., 2009). Proline-directed kinases, such as Cdk5, MAPKs, and glycogen synthase kinase 3, have been shown to be implicated in the aberrant phosphorylation of NF, but the role of phosphatases has not yet been explored. Compared with the hundreds of known kinases, there are only a handful of phosphatases, and each of them must dephosphorylate a wide range of protein substrates. Dephosphorylation of Tau has been extensively studied. PP1, PP2A, and $\mathrm{PP} 2 \mathrm{~B}$ have all been shown to dephosphorylate Tau in vitro. In transgenic mice with reduced PP2A activity, Tau becomes hyperphosphorylated and redistributed in CNS neurons (Kins et al., 2003). This is consistent with the reduced expression of the phosphatase in AD. Previous studies have suggested that Ser/Thr phosphatases are involved in neurodegeneration (VogelsbergRagaglia et al., 2001). We found that the PP2A activity is reduced in ALS spinal cord and AD brain. In this study, we have used specific inhibitors to study the NF dephosphorylation in cortical neurons. The PP1/PP2A inhibitors, such as OA and microcystin LR, cause hyperphosphorylation of NF in primary cortical cultures. Treatment of cortical neurons with Fos, a more selective inhibitor of PP2A, results in the perikaryal hyperphosphorylation of NF. Conversely, the PP2B-specific inhibitor cyclosporine A did not affect the perikaryal hyperphosphorylation of NF. Previous studies performed by us and in other laboratories has shown that PP2A is the major NF phosphatase, and PP2B contributes less toward the dephosphorylation of NF. In addition, Strack et al. (1997) reported that PP2A and PP1 were associated with the spinal cord NF fraction, but PP2B was found exclusively in the low-molecular-weight fraction. They attributed $75 \%$ of NF dephosphorylation to $\mathrm{PP} 2 \mathrm{~A}$ and the rest to PP1. We performed dose-dependent analysis of cyclosporine A to verify the neurofilament phosphorylation and observed no effect on perikaryal phosphorylation of NF. In previous studies using the squid giant axon system, we have shown that PP2B is abundant in the axons compared with cell bodies (Krinks et al., 1988). PP2B levels and activity are shown to be increased in AD brain (Liu et al., 2005).

We show here that Pin 1 affects the perikaryal phosphorylation of NF by PP2A in vitro and in primary neuronal cultures. Pin 1 prevents the dephosphorylation of NF by PP2A in vitro.

Inhibition of Pin 1 levels (Pin 1 siRNA) as well as Pin 1 activity (DN Pin1) inhibits the OA-induced perikaryal phosphorylation of NF. This study further shows that OA-mediated hyperphosphorylation of NF is not attributable to the activation of JNK, ERK, or Cdk5 but is a consequence of dephosphorylation of NF. In $\mathrm{AD}$, the PP2A activity is downregulated (Sontag et al., 2004; Liu et al., 2005). Our study also shows that the KSP tail domain dephosphorylation of NF-M/H by PP2A is regulated by Pin1.

Previous studies by Mushynski and coworkers have reported an increase in phosphorylation of the N-terminal domain of NF-L and NF fragmentation in OA-treated DRG neurons. The punctuate appearance of axonal NF could be attributable to the fragmentation of hyperphosphorylation of these molecules as suggested previously (Sacher et al., 1992, 1994). OA has been noted to disrupt the NF network in DRG neurons and increase deposits of NF subunits in $\mathrm{nb} 2 \mathrm{a} / \mathrm{d} 1$ neuroblastoma cells (Shea et al., 1993).

NF phosphorylation has been shown to regulate the axonal transport of newly synthesized NFs. Shea et al. (2004) reported that the serine/threonine kinase $\mathrm{Cdk} 5$ regulates phosphorylation and axonal transport of NFs. They found that increasing Cdk5 activity in cultured chicken dorsal root ganglion neurons increases phosphorylation of the NFs, causes abnormal deposits of aggregated NFPs in the perikaryon, and reduces their axonal transport. Furthermore, they show that injection of OA into murine retina fostered the appearance of phospho-NF accumulations within the perikarya in situ and slowed the axonal transport (Jung and Shea, 2004). Previous studies performed with EGFP- 
NF-M have shown that NFs are transported rapidly with frequent pauses (Wang et al., 2000). Alterations of anterograde axonal transport and fragmentation have been observed in patients and animal models of ALS and other neurodegenerative diseases. Phosphorylated NF protein accumulations in the perikarya and proximal axons of motor neurons have been shown to block axonal transport of cytoskeletal proteins and mitochondria and eventually cause axonal degeneration (Hoffman and Lasek, 1975). Sporadic ALS patients have NF-H alleles with deletions in the KSP repeat domain, which suggests that altered phosphorylation may indeed be a cause for NF accumulations (Figlewicz et al., 1994., Julien, 1995). Our study reveals that inhibition of PP2A by $\mathrm{OA}$ affects axonal transport of transfected NF-H and induces accumulation of phospho-NF-M/H in these loci, whereas inhibition of Pin 1 rescues this effect. These findings indicate that $\mathrm{Pin} 1$ regulates NF dynamics.

Based on our findings, we propose a model for topographic phosphorylation of NF (Fig. 12). In normal neurons, PP2A activity is high in cell bodies, and phosphorylation of NF occurs selectively in axonal compartments. Glial-axonal interactions may activate the proline-directed Ser/Thr kinases; phosphorylation of S/T-P residues of the tail domain of NF-M/H occurs in axons (Dashiell et al., 2002). The phosphorylation of initial S/T-P residues in the tail domain may induce spontaneous transitions to cis conformation for some of the peptidyl-prolyl bonds. Pin1 binding to phospho-S/T-P sites converts cispeptidyl bonds to the trans configuration. Thus, Pin1 stabilizes the NF tail domain phosphorylation of S/T-P motifs in the axonal compartment. Pin 1 facilitates NF phosphorylation in the axonal compartment of almost all S/T-P residues. However, when PP2A activity is inhibited, $\mathrm{NF}-\mathrm{M} / \mathrm{H}$ are phosphorylated on S/T-P sites within the cell body compartment. This is consistent with the known requirement of Pin 1 for S/T phosphorylation before its binding and isomerization of such sites. Aggregated phospho-NF proteins accumulate in the cell bodies and proximal axons and impair NF axonal transport. Accordingly, inhibition of Pin 1 inhibits the OA-induced hyperphosphorylation of NF and rescues the axonal transport of NF.

Pin 1 action on its target proteins depends on their structure. Pin 1 facilitates the dephosphorylation of Tau by PP2A at a specific single residue, Thr 231 (Lu et al., 1999). In contrast, Pin1 inhibits the dephosphorylation of multiple SP repeats of RNA polymerase C-terminal domain (CTD) by FCP1 phosphatase (Xu et al., 2003). Similar to CTD, rat NF-H has 52 SP repeats in the tail domain. The mechanism of Pin 1 action on NF appears to
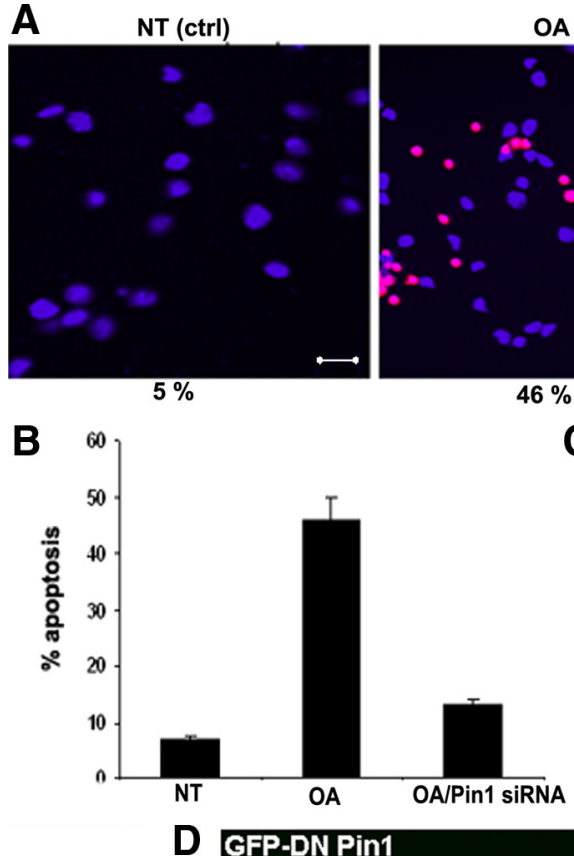

OA

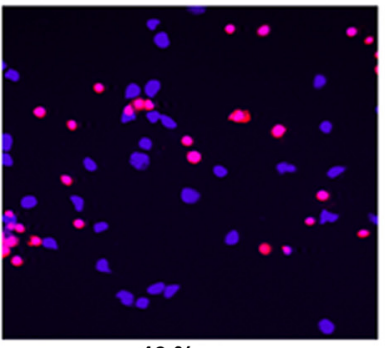

$46 \%$
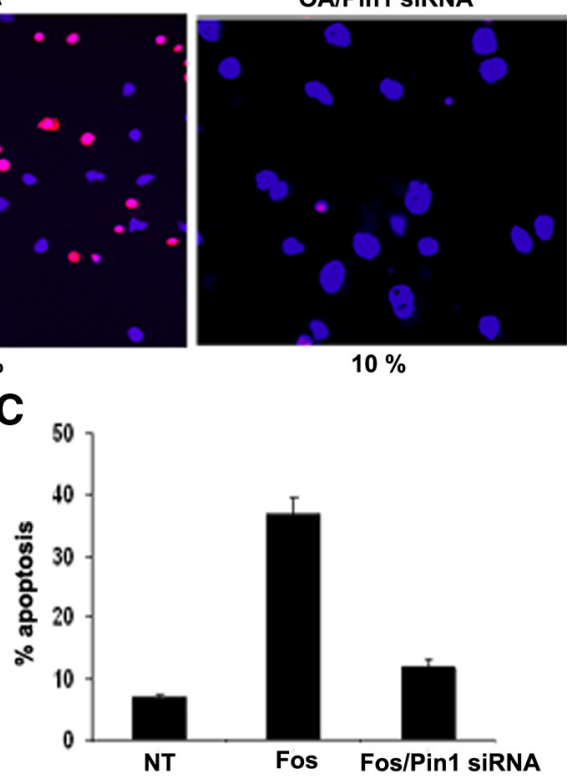

$10 \%$

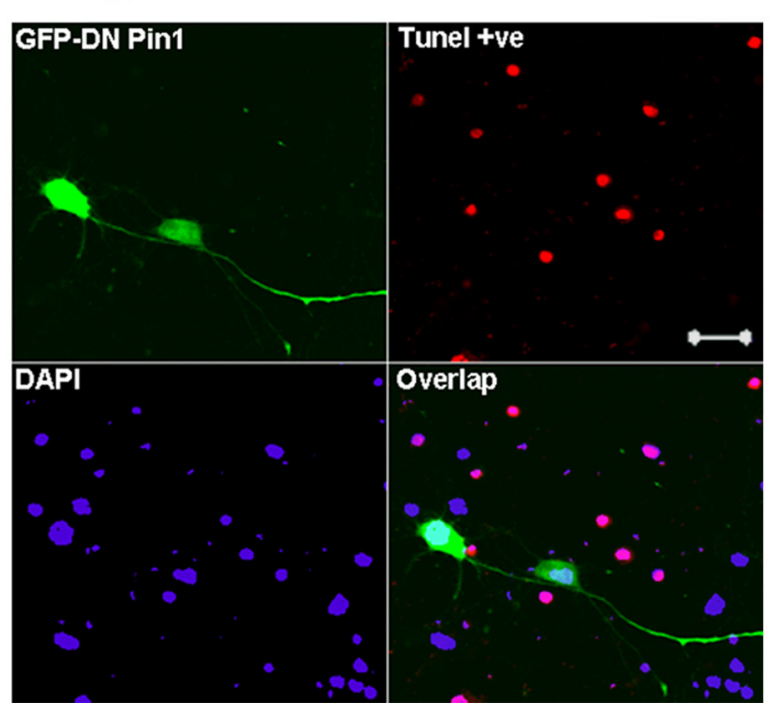

Figure 11. Inhibition of Pin 1 reduces $0 \mathrm{~A} /$ Fos-induced neuronal death. $A$, Presence of apoptotic neurons examined by TUNELtetramethylrhodamine red staining in 7 DIC cortical neurons. Nuclei were counterstained using DAPI (blue). TUNEL-positive neurons were increased during $0 \mathrm{~A}$ treatment for $5 \mathrm{~h}$ and declined in $0 \mathrm{~A}$-treated neurons transfected with Pin 1 siRNA. Scale bar, $20 \mu \mathrm{m}$ The quantization in the bar graph $(\boldsymbol{B})$ represents TUNEL-positive counts from four separate experiments, in which 12 independent $35 \%$ during exposure to $F$ os, and this was reduced to $12 \%$ in neurons transfected with Pin 1 siRNA and subjected to Fos. D, OA-mediated neuronal apoptosis is reduced by overexpression of DN Pin1. Five-day-old cortical neurons were transfected with DN Pin 1 and, after $24 \mathrm{~h}$, were treated with $0.1 \mu \mathrm{m}$ OA for $5 \mathrm{~h}$. The GFP-DN Pin1-transfected neurons survive OA-induced cell death. Scale bar, $20 \mu \mathrm{m}$.

be similar to RNA polymerase II. This raises an intriguing possibility that proteins with multiple SP repeats have similar mechanisms of Pin 1 action.

Protein-protein interactions have been reported to sterically inhibit protein phosphatase activity (Palancade et al., 2004). For example, Pin 1 binding to multiphosphorylated transcription factor NFAT (nuclear cofactor of activated T cells) inhibits its additional dephosphorylation by calcineurin. The binding of Pin 1 to its phosphorylated substrate can inhibit its subsequent dephosphorylation by specific protein phosphatases. This inhibition might be attributable to either a direct masking of the phosphorylated site(s) targeted by the phosphatase or a failure to recruit the phosphatase by masking the docking site within the substrate. 

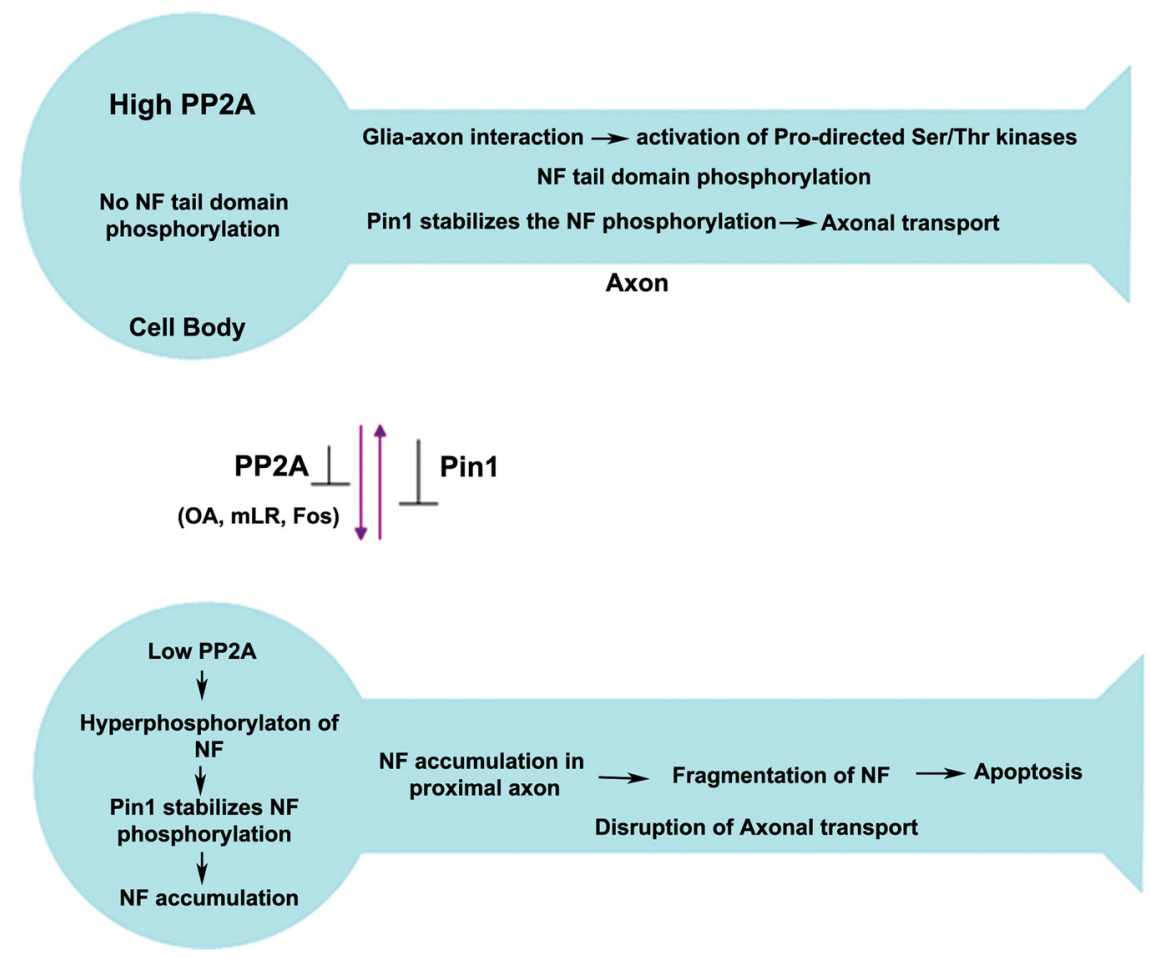

Figure 12. Role of Pin1 in the progression of compartment-specific NF-M/H phosphorylation. Top, In normal neurons, the NF phosphorylation is selective in the axonal compartment in normal neurons. After NF protein synthesis, higher activity of PP2A in cell bodies inhibits the NF tail domain phosphorylation. Although Pin1 is localized in cell bodies, it cannot act on the non-S/T-P phosphorylated proteins. During assembly of NF in axonal hillock region, NFs are transported by slow axonal transport. In the axonal compartment, the axonal- glial interaction activates the Ser/Thr kinases and phosphorylates some of pSer/Thr-Pro residues. The phosphorylation of these residues renders the phospho-Ser/Thr-Pro to remain in cis configuration and blocks additional phosphorylation. However, Pin1 induces cis-trans isomerization, increases the accessibility of the Ser/Thr kinases, and stabilizes the NF phosphorylation. Because of the high PP2A activity, there is no NF phosphorylation in the cell bodies. Bottom, Inhibition of PP2A activity leads to aberrant perikaryal hyperphosphorylation of NF proteins in cell bodies. Pin 1 stabilizes the NF phosphorylation in the cell bodies, phospho-NF proteins are accumulated in the cell bodies and proximal axons, and NF transport is impaired. This is consistent with the observation that PP2A activity is reduced in AD brain and ALS spinal cord with higher accumulations of phospho-NF in the perikarya.

Juglone has been used previously as a pharmacological Pin1 inhibitor. Accumulating evidence suggests that juglone is a nonspecific inhibitor of Pin1, because it also blocks transcription (Chao et al., 2001). In addition, juglone inhibits numerous parvulins as well as other enzymes with Cys residues in their catalytic domains (Fila et al., 2008). A specific Pin1 inhibitor has not been identified so far. To inhibit cellular Pin1 function, we used DN Pin1 (Ryo et al., 2002; Lam et al., 2008). We also used Pin1 siRNA to specifically inhibit Pin1 levels.

Our finding that Pin1 regulates dephosphorylation of NF mediated by PP2A indicates that Pin 1 has a direct role in phosphoNFP aggregation in AD, ALS, and related neurodegenerative disorders. Pin 1 also increases the phosphorylation of NF by proline-directed kinases, such as MAPKs, Cdk5, and JNK3 (Rudrabhatla et al., 2008). This study suggests a novel mechanism whereby Pin 1 not only inhibits dephosphorylation but induces sequential phosphorylation of S/T-P residues in a protein. Exactly how this occurs is unknown, but it is consistent with previous findings that Pin 1 regulates the function of its substrate by different mechanisms ( $\mathrm{Lu}$ and Zhou, 2007; Rudrabhatla and Pant, 2009). Thus, phosphorylation-specific Pin1 could be an attractive therapeutic target to inhibit the perikaryal hyperphosphorylation of NF caused by downregulation of PP2A activity in $\mathrm{AD}, \mathrm{PD}, \mathrm{ALS}$, and/or related pathology.

\section{References}

Ahlijanian MK, Barrezueta NX, Williams RD, Jakowski A, Kowsz KP, McCarthy S, Coskran T, Carlo A, Seymour PA, Burkhardt JE, Nelson RB, McNeish JD (2000) Hyperphosphorylated tau and neurofilament and cytoskeletal disruptions in mice overexpressing human p25, an activator of cdk5. Proc Natl Acad Sci U S A 97:2910-2915.

Chao SH, Greenleaf AL, Price DH (2001) Juglone, an inhibitor of the peptidyl-prolyl isomerase Pin 1, also directly blocks transcription. Nucleic Acids Res 29:767-773.

Chin SS, Liem RK (1990) Transfected rat highmolecular-weight neurofilament (NF-H) coassembles with vimentin in a predominantly nonphosphorylated form. J Neurosci 10:37143726.

Dashiell SM, Tanner SL, Pant HC, Quarles RH (2002) Myelin-associated glycoprotein modulates expression and phosphorylation of neuronal cytoskeletal elements and their associated kinases. J Neurochem 81:1263-1272.

de Waegh SM, Lee VM, Brady ST (1992) Local modulation of neurofilament phosphorylation, axonal caliber and slow axonal transport by mylenating Schwann cells. Cell 68:451 463.

Eagles PAM, Pant HC, Gainer H (1990) Neurofilaments. In: Cellular and molecular biology of intermediate filaments (Goldman RD, Steinert PM, eds), pp 951-958. New York: Plenum.

Figlewicz DA, Krizus A, Martinoli MG, Meininger V, Dib M, Rouleau GA, Julien JP (1994) Familial amyotrophic lateral sclerosis: a review. Hum Mol Genet 3:1757-1761.

Fila C, Metz C, van der Sluijs P (2008) Juglone inactivates cysteine-rich proteins required for progression through mitosis. J Biol Chem 283:21714-21724.

Goldman JE, Yen SH (1986) Cytoskeletal protein abnormalities in neurodegenerative diseases. Ann Neurol 19:209-223.

Grant P, Pant HC (2000) Neurofilament protein synthesis and phosphorylation. J Neurocytol 29:843-872.

Green SL, Westendorf JM, Jaffe H, Pant HC, Cork LC, Ostrander EA, Vignaux F, Ferrell JE Jr (2005) Allelic variants of the canine heavy neurofilament (NFH) subunit and extensive phosphorylation in dogs with motor neuron disease. J Comp Pathol 132:33-50.

Guan L, Song K, Pysz MA, Curry KJ, Hizli AA, Danielpour D, Black AR, Black JD (2007) Protein kinase C-mediated down-regulation of cyclin D1 involves activation of the translational repressor $4 \mathrm{E}-\mathrm{BP} 1$ via a phosphoinositide 3-kinase/Akt-independent, protein phosphatase 2A-dependent mechanism in intestinal epithelial cells. J Biol Chem 282:14213-14225.

Guru SC, Shetty KT, Shankar SK (1991) Effect of chronic ethanol ingestion on phosphate content of NF proteins and NF associated protein phosphatase in rat spinal cord. Neurochem Res 16:1193-1197.

Hirano A (1991) Cytopathology of amyotrophic lateral sclerosis. Adv Neurol 56:91-101.

Hirano A, Donnenfeld H, Sasaki S, Nakano I (1984) Fine structural observations of neurofilamentous changes in amyotrophic lateral sclerosis. J Neuropathol Exp Neurol 43:461-470.

Hoffman PN, Lasek RJ (1975) The slow component of axonal transport. Identification of major structural polypeptides of the axon and their generality among mammalian neurons. J Cell Biol 66:351-366.

Jaffe H, Veeranna, Pant HC (1998) Characterization of serine and threonine phosphorylation sites in beta-elimination/ethanethiol addition-modified proteins by electrospray tandem mass spectrometry and database searching. Biochemistry 37:16211-16224.

Julien JP (1995) A role of neurofilaments in the pathogenesis of amyotrophic lateral sclerosis. Biochem Cell Biol 73:593-597.

Jung C, Shea TB (2004) Neurofilament subunits undergo more rapid trans- 
location within retinas than in optic axons. Brain Res Mol Brain Res 122:188-192.

Kesavapany S, Patel V, Zheng YL, Pareek TK, Bjelogrlic M, Albers W, Amin N, Jaffe H, Gutkind JS, Strong MJ, Grant P, Pant HC (2007) Inhibition of Pin1 reduces glutamate-induced perikaryal accumulation of phosphorylated neurofilament-H in neurons. Mol Biol Cell 18:3645-3655.

Kins S, Kurosinski P, Nitsch RM, Götz J (2003) Activation of the ERK and JNK signaling pathways caused by neuron-specific inhibition of PP2A in transgenic mice. Am J Pathol 163:833-843.

Krinks MH, Klee CB, Pant HC, Gainer H (1988) Identification and quantification of calcium-binding proteins in squid axoplasm. J Neurosci 8:2172-2182.

Lam PB, Burga LN, Wu BP, Hofstatter EW, Lu KP, Wulf GM (2008) Prolyl isomerase Pin1 is highly expressed in Her2-positive breast cancer and regulates erbB2 protein stability. Mol Cancer 7:91.

Lee VM, Otvos L Jr, Carden MJ, Hollosi M, Dietzschold B, Lazzarini RA (1988) Identification of the major multiphosphorylation site in mammalian neurofilaments. Proc Natl Acad Sci U S A 85:1998-2002.

Liu F, Grundke-Iqbal I, Iqbal K, Gong CX (2005) Contributions of protein phosphatases PP1, PP2A, PP2B and PP5 to the regulation of tau phosphorylation. Eur J Neurosci 22:1942-1950.

Lu KP, Zhou XZ (2007) The prolyl isomerase PIN1: a pivotal new twist in phosphorylation signaling and disease. Nat Rev Mol Cell Biol 8:904-916.

Lu PJ, Wulf G, Zhou XZ, Davies P, Lu KP (1999) The prolyl isomerase Pin1 restores the function of Alzheimer-associated phosphorylated tau protein. Nature 399:784-788.

Manetto V, Perry G, Tabaton M, Mulvihill P, Fried VA, Smith HT, Gambetti P, Autilio-Gambetti L (1988) Ubiquitin is associated with abnormal cytoplasmic filaments characteristic of neurodegenerative diseases. Proc Natl Acad Sci U S A 85:4501-4505.

Mata M, Kupina N, Fink DJ (1992) Phosphorylation dependent neurofilament epitopes are reduced at the node of Ranvier. J Neurocytol 21:199-210.

Nixon RA, Lewis SE, Marotta CA (1987) Posttranslational modification of neurofilament proteins by phosphate during axoplasmic transport in retinal ganglion cell neurons. J Neurosci 7:1145-1158.

Palancade B, Marshall NF, Tremeau-Bravard A, Bensaude O, Dahmus ME, Dubois MF (2004) Dephosphorylation of RNA polymerase II by CTDphosphatase FCP1 is inhibited by phospho-CTD associating proteins. J Mol Biol 335:415-424.

Rao MV, Nixon RA (2003) Defective neurofilament transport in mouse models of amyotrophic lateral sclerosis: a review. Neurochem Res 28:1041-1047.

Rudrabhatla P, Pant HC (2009) Phosphorylation-specific peptidyl-prolyl isomerization of neuronal cytoskeletal proteins by Pin1: implications for therapeutics in neurodegeneration. J Alzheimers Dis. Advance online publication. Retrieved November 12, 2009. doi:10.3233/JAD-2009-1243.

Rudrabhatla P, Zheng YL, Amin ND, Kesavapany S, Albers W, Pant HC (2008) Pin1-dependent prolyl isomerization modulates the stressinduced phosphorylation of high molecular weight neurofilament protein. J Biol Chem 283:26737-26747.

Ryo A, Liou YC, Wulf G, Nakamura M, Lee SW, Lu KP (2002) PIN1 is an E2F target gene essential for Neu/Ras-induced transformation of mammary epithelial cells. Mol Cell Biol 22:5281-5295.

Sacher MG, Athlan ES, Mushynski WE (1992) Okadaic acid induces the rapid and reversible disruption of the neurofilament network in rat dorsal root ganglion neurons. Biochem Biophys Res Commun 186:524-530.

Sacher MG, Athlan ES, Mushynski WE (1994) Increased phosphorylation of the amino-terminal domain of the low molecular weight neurofilament subunit in okadaic acid-treated neurons. J Biol Chem 269:18480-18484.

Schilling K, Duvernoy C, Keck S, Pilgrim C (1989) Detection and partial characterization of a developmentally regulated nuclear antigen in neural cells in vitro and in vivo. J Histochem Cytochem 37:241-247.

Shea TB, Paskevich PA, Beermann ML (1993) The protein phosphatase inhibitor okadaic acid increases axonal neurofilaments and neurite caliber, and decreases axonal microtubules in NB2a/d1 cells. J Neurosci Res 35:507-521.

Shea TB, Zheng YL, Ortiz D, Pant HC (2004) Cyclin-dependent kinase 5 increases perikaryal neurofilament phosphorylation and inhibits neurofilament axonal transport. J Neurosci Res 76:795-800.

Shetty KT, Veeranna, Guru SC (1992) Effect of chronic ethanol ingestion on phosphate content of neurofilament proteins and neurofilament associated protein phosphatase in rat spinal cord. Neurosci Lett 137:83-86.

Sim ATR (1991) The regulation and function of protein phosphatases in the brain. Mol Neurobiol 5:229-246.

Sontag E, Luangpirom A, Hladik C, Mudrak I, Ogris E, Speciale S, White CL 3rd. (2004) Altered expression levels of the protein phosphatase 2A ABalphaC enzyme are associated with Alzheimer disease pathology. J Neuropathol Exp Neurol 63:287-301.

Sternberger NH, Sternberger LA, Ulrich J (1985) Aberrant neurofilament phosphorylation in Alzheimer disease. Proc Natl Acad Sci U S A 82:42744276.

Strack S, Westphal RS, Colbran RJ, Ebner FF, Wadzinski BE (1997) Protein serine/threonine phosphatase 1 and $2 \mathrm{~A}$ associate with and dephosphorylate neurofilaments. Brain Res Mol Brain Res 49:15-28.

Strong MJ, Kesavapany S, Pant HC (2005) The pathobiology of amyotrophic lateral sclerosis: a proteinopathy? J Neuropathol Exp Neurol 64:649-664.

Tokutake S, Hutchison SB, Pachter JS, Liem RK (1983) A batchwise purification of neurofilament proteins. Anal Biochem 135:102-105.

Veeranna, Shetty KT, Link WT, Jaffe H, Wang J, Pant HC (1995) Neuronal cyclin-dependent kinase-5 phosphorylation sites in neurofilament protein (NF-H) are dephosphorylated by protein phosphatase 2A. J Neurochem 64:2681-2690.

Veeranna, Amin ND, Ahn NG, Jaffe H, Winters CA, Grant P, Pant HC (1998) Mitogen-activated protein kinases (Erk1,2) phosphorylate LysSer-Pro (KSP) repeats in neurofilament proteins NF-H and NF-M. J Neurosci 18:4008-4021.

Vogelsberg-Ragaglia V, Schuck T, Trojanowski JQ, Lee VM (2001) PP2A mRNA expression is quantitatively decreased in Alzheimer's disease hippocampus. Exp Neurol 168:402-412.

Wang L, Ho CL, Sun D, Liem RKH, Brown A (2000) Rapid movement of axonal neurofilaments interrupted by prolonged pauses. Nat Cell Biol 2:137-141.

Weigum SE, García DM, Raabe TD, Christodoulides N, Koke JR (2003) Discrete nuclear structures in actively growing neuroblastoma cells are revealed by antibodies raised against phosphorylated neurofilament proteins. BMC Neurosci 4:6.

Wharton S, Ince PG (2003) Pathology of motor neuron disorders. In: Motor neuron disorders blue books of practical neurology (Shaw PJ, Strong MJ, eds), pp 17-49. Philadelphia: Butterworth Heinemann.

Xiao S, McLean J, Robertson J (2006) Neuronal intermediate filaments and ALS: a new look at an old question. Biochim Biophys Acta 1762:10011012.

Xu YX, Hirose Y, Zhou XZ, Lu KP, Manley JL (2003) Pin1 modulates the structure and function of human RNA polymerase II. Genes Dev 17:2765-2776.

Yabe JT, Pimenta A, Shea TB (1999) Kinesin-mediated transport of neurofilament protein oligomers in growing axons. J Cell Sci 112:3799-3814.

Yaffe MB, Schutkowski M, Shen M, Zhou XZ, Stukenberg PT, Rahfeld JU, Xu J, Kuang J, Kirschner MW, Fischer G, Cantley LC, Lu KP (1997) Sequence-specific and phosphorylation-dependent proline isomerization: a potential mitotic regulatory mechanism. Science 278:1957-1960.

Zheng YL, Amin ND, Rudrabhatla P, Kesavapany S, Pant HC (2009) Neuronal cytoskeleton regulation and neurodegeneration. In: Current hypotheses and research milestones in Alzheimer's disease (Maccioni RB, Perry G, eds), pp 1-16. New York: Springer.

Zhou XZ, Kops O, Werner A, Lu PJ, Shen M, Stoller G, Küllertz G, Stark M, Fischer G, Lu KP (2000) Pin1-dependent prolyl isomerization regulates dephosphorylation of Cdc25C and tau proteins. Mol Cell 6:873-883. 